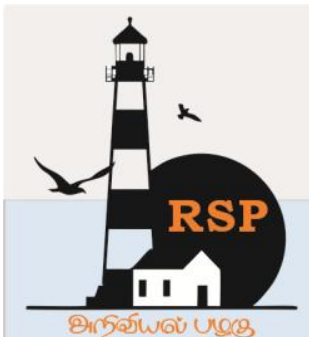

INTERNATIONAL RESEARCH JOURNAL ON ADVANCED SCIENCE HUB

\title{
UVC light disinfectant on Biometric system
}

Mr. Praveen B, Mr. Prasanth M, Mr. Krishna Prasad L, Dr. S. Balasubramanian.

Mr. Praveen B, Dept. of Mechanical Engineering, Kumaraguru College of Technology, Tamil Nadu, India. Mr. Prasanth M, Dept. of Mechanical Engineering, Kumaraguru College of Technology, Tamil Nadu, India Mr. Krishnaprasad L, Dept. of Mechanical Engineering, Kumaraguru College of Technology, Tamil Nadu, India.

Dr. S. Balasubramanian, Associate Professor, Dept. of Mechanical Engineering, Kumaraguru College of Technology, Tamil Nadu, India.

praveen.18me@kct.ac.in ${ }^{1}$

\begin{abstract}
Social infection is a major contribution for human disaster. Biometric devices are to verify one's identity for each and every one is having unique biological traits. In many circumstances, recording the identification through fingerprint has become important and an unavoidable one. But placing fingers on the same biometrics system serves as a means of spreading the virus quickly. An innovative device using UVC (Ultra Violet C) light on the finger impression, disinfects the virus between every press. The whole device with the forced air arrangement for disposing the disinfected virus shall be attached to an existing fingerprint system. Thus, this project aims in using the regular biometrics system safely without the spread of coronavirus.
\end{abstract}

Keywords: UVC (Ultra Violet C) Disinfectant Light, Biometric Sensor, Forced air arrangement, Social Infection.

\section{Introduction}

The current pandemic covid-19is spreading outside and its communication is effective. It spreads from person to person without any initial warning/trail. Researchers found that the spread of these viruses is by physical contact. Organizations have now realized the use of biometrics for attendance and security purposes. One of the security devices that many people use in some circumstances is the biometric sensor. They are also widely used in workplaces, schools, colleges for attendance purposes. Hence, they have been stopped to ensure security to human life. Using Ultraviolet C (UVC) light as a disinfectant, stops the spread of the virus [1]. This paper deals with the method to bring back the use of biometrics by ensuring safety and reducing the threat of virus spread.

\subsection{COVID - 19}

COVID-19, Corona virus Disease 2019, a deadly disease that shook the whole world, leading to worldwide Lockdown like no years before. Then this COVID-19, with no cure for its effects have also started to spread worldwide.

The diameter of this deadly virus is around $10^{-9} \mathrm{~m}=1 \mathrm{~nm}$. Club-shaped glycoprotein spikes look like a crown on the envelope. Thus, this virus got its name corona[2]Proteins associated with these nucleic acids are called Nucleocapsid, and 
the nucleic acids in this virus are either helical or tubular. This Nucleocapsid is the main reason for its replications.

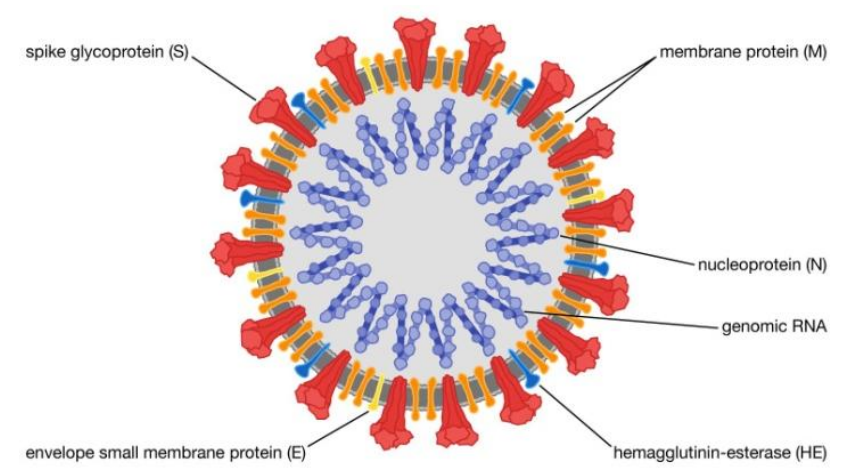

Fig.1. Coronavirus

\section{Case Study}

Delhi Government, on 5th March, 2020 stopped the use of the Biometrics Attendance system in offices. In order to stop the spread of the virus a letter has been written to the Principal secretaries, secretaries, Municipal Corporations and Autonomous bodies.

On 17th February, 2020 biometric attendance system was denied in Maharishi Valmiki Hospital, Delhi. Many employees of the hospital complained to authorities that using the same biometric system is "Psychological unease" due to COVID-19.

Hon'ble Prime Minister Shri. Narendra Modi instructed to stop the use of Biometric Attendance. Following his words, Sports Authority of India, National Green Tribunal, Maharashtra, Goa, Punjab have quit the usage of this system.

Soon the offices started to reopen, employees feared that the Biometric System would pose a big threat to their safety. Hence "Turn off Biometric Attendance" became the one of several words for nearly 180 in 200 IT Companies, Says Hyderabad police Commissioner.

\section{Literature Survey}

Kreiner et al.(2018)[6], used Ultraviolet $C$ rays, to sterilize microorganisms He used three devices for this purpose. 1. UVC emitting unit, 2. A processor, 3. Computer medium. His method was capable of performing operation once a movement in the proximity sensor is detected. This job was controlled by the processor he deployed. The computer medium was set up in such a way that it stores instructions and keeps a track of it and they are executed by the processor to perform operations.

Garcia et al.(2010) [7], He devised a model having a UVC source, from which UVC rays pass through thus reducing the action of microorganisms, such as virus, bacteria, moulds and dust mites. He also devised a model for reducing the heat dissipation also ensuring safety of the persons nearby.

Harmon et al. (2010)[8], designed a mobile UVC disinfectant. The person using this system can move the device wherever he wants to sterilize the microorganisms. His device also can keep track of the amount of light that should fall on the surface. He used a UVC source, indicator, distance detector and a microprocessor. The microprocessor he used will detect the distance between the surface and UVC light source for calculating the amount of light that should be passed over the surface. The indicator shows the amount of light passing.

Ervin Keith.(2018) [9], his method is based on selecting the target body first on which the UV light is to be concentrated. Then, based on the type of target, the intensity of the UV light is subjected then the time period for passing the UV rays is then analysed. Once the trial is done the setting is saved for the next future use.

Rosenthal et al. (2001) [10] found a method for sanitizing hands using waterless methods. His method is free from any liquids as he uses ozone, ultraviolet rays, visible and near visible lights for inactivating the disease-causing microorganisms. This is done by ozone produced by short wavelengths of ultraviolet rays thus produced. This is made from a standing device like structure where ultraviolet rays of $184 \mathrm{~nm}$ oxides atmospheric air. Thus, oxygen oxidizes to form ozone, which is captured to sanitize hands.

\section{UVC}


Ultraviolet Germicidal Irradiation is a method that uses wavelengths that are small, probably ultraviolet to kill or subdue the microorganisms by destroying the nucleic acids, thusdestabilizing their DNA so that it becomes unable to perform its vital cellular functions. [5]

The ultraviolet rays majorly lie in between the visible and X-ray spectrum. There are 3 types according to the emission of UV light are as follows

$$
\begin{aligned}
& \text { 1. UV-A (315-400nm) } \\
& \text { 2. UV-B (280-315nm) } \\
& \text { 3. UV-C (100-280nm) }
\end{aligned}
$$

UVC light proves effective in disinfecting the virus and is also human friendly.

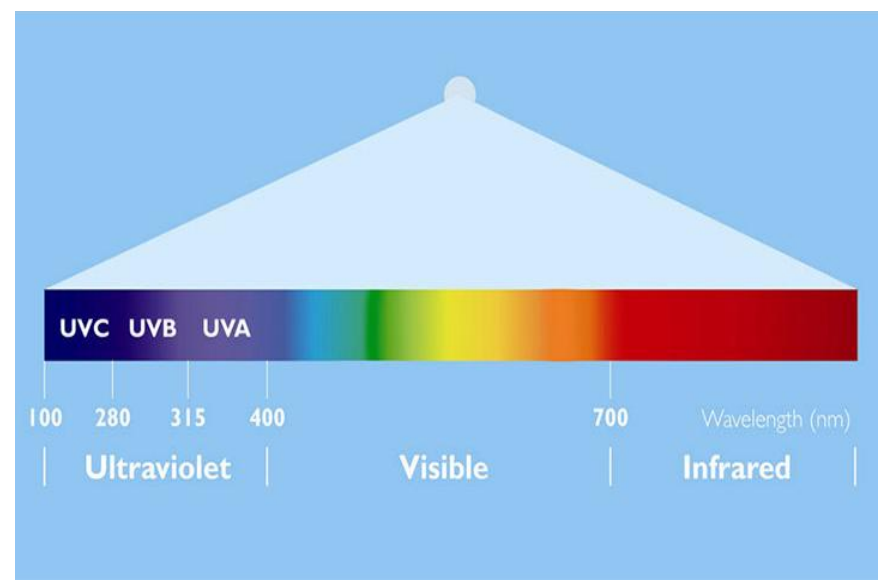

Fig.2. UV Light Spectrum

\section{Method}

The UVC light is readily available in the market that can be purchased and used for this purpose. This light is made to fix on the surface and focus over the biometrics sensor area. When a person uses this biometric system, there is a disturbance caused by the fingers of the person who uses it. This motion is sensed by the ultrasonic sensor kept on the head of the UVC lamp. Delay time is set up to ensure safety of the person for the exposure of UV rays. Though UVC rays do not affect the skin, for safety purpose delay time is specified. Only after the delay time, the UV rays are focussed on the biometrics system. Then after a few seconds, the UVC rays are switched off again.

UV rays penetrate through surfaces, but this depends on the chemical composition of the materials. Mostly the greater wavelength of UV rays may penetrate through. Using smaller wavelength (i.e.) UVC light of around $207 \mathrm{~nm}$ to $222 \mathrm{~nm}$ has no impact on the human body. It is not exposed on body parts and has only impact on the fingerprint sensor to kill or subdue the action of virus if any, is present in the glass surface of the biometric device.[4]

Acrylic plastics, will not allow UVC lights of wavelengths $100 \mathrm{~nm}-290 \mathrm{~nm}$ to pass through. Hence Acrylic Sheets of 3 to $5 \mathrm{~mm}$ thickness are used on the head of the UVC lamp to cover the excess areas. The use of acrylic plastics will prevent over exposure of UVC lights. UVC won't pass through glass so it doesn't cause any damage to the biometric sensor. Also, it is ensured that the UV rays from the head only focus on the glass surface where the person keeps his finger for his recognition.

Coronavirus has the capability to stick to a surface for several hours to days and it depends on the type of material the surface is made of. So, it becomes essential for disposal of the virus particles present on the surface. Taking Coronavirus into consideration, it can stay on metal bodies for 5 days, wood for 4 days, plastics for 3 to 4 days, stainless steel for 2 to 3 days, cardboard for 24 hours, copper for 4 hours, Aluminium for 2 to 8 hours, glass for 5 days, ceramic bodies for 5 days[11].

This biometric device is made of plastics mostly and the fingerprint sensor is made of glass. So, this deadly coronavirus can stay alive for nearly 3 to 4 days on plastics and 5 days on glass. This seems to be a big problem for continuing the usage of this system. Hence it is necessary to ensure that the virus doesn't stick to the surface of the glass on the fingerprint sensor and the plastic region of the biometric device is made of. Once the UVC light disposes the microbes the blower in this system is used to wipe away the remaining microbes present.

Compressed air is used to wipe away the sterilized virus, i.e. dead cells, if any on the surface. This compressed air will be blown from a device such as a blower or a fan at a speed more than 600rpm. When the fan or a blower rotates at a 
speed of 600rpm wipes away the dead virus or inactivated virus over the surface, thus preventing the dead cells from entering the fingers of the next user.

\begin{tabular}{|c|c|c|}
\hline S. No & Description & $\begin{array}{c}\text { Material/ } \\
\text { Specification }\end{array}$ \\
\hline 1. & $\begin{array}{c}\text { Biometric } \\
\text { reader }\end{array}$ & Fibre plastic \\
\hline 2. & $\begin{array}{c}\text { UVC light } \\
\text { (Germicidal head } \\
\text { lamp) }\end{array}$ & $\begin{array}{c}\text { Borosilicate } \\
\text { glass \& quartz }\end{array}$ \\
\hline 3. & Ultrasonic sensor & $\begin{array}{c}\text { Piezoelectric } \\
\text { Crystals. }\end{array}$ \\
\hline 4. & Fan or Blower & RPM> $>600$ \\
\hline
\end{tabular}

\section{Table.1. Materials Required}

Dosage and intensity of the UV light are important before using UV light. Certain amount of light is enough to subdue the virus action. Hence over exposure is also reduced.

Intensity can be calculated by the formula,

$$
I=P * A
$$

Where ' $\mathrm{P}$ ' is power consumed and ' $\mathrm{A}$ ' is the area exposed. Accurate results can be obtained by using a UVC detector. For Example, Zenith detector can be used for this purpose. The detector when placed on the surface detects the UV intensity and displays result in $\mu \mathrm{W} / \mathrm{cm}^{2}$.

Dosage refers to the effectiveness of the rays on the Target body.

$$
\text { Dosage of } \mathrm{UV}=\mathrm{I} * \mathrm{t}
$$

Where ' $\mathrm{I}$ ' is the Intensity of $\mathrm{UV}$ in $\mu \mathrm{W} / \mathrm{cm}^{2}$ and ' $\mathrm{t}$ ' is the time of exposure in seconds.

Biax germicidal lamps can be used as a UVC source for this purpose that consumes $18 \mathrm{~W}$ Power and has a UV irradiance of $51 \mu \mathrm{W} / \mathrm{cm}^{2}$ (i.e.) the intensity. Typical UV dosage is the minimum dose required to kill the microbial action. The typical UV doserequired to stop a virus action is $40 \mathrm{~mJ} / \mathrm{cm}^{2}$. Biax germicidal Lamp has a standard UV dosage (for s1-meter distance from the target) greater than $40 \mathrm{~mJ} / \mathrm{cm}^{2}$.

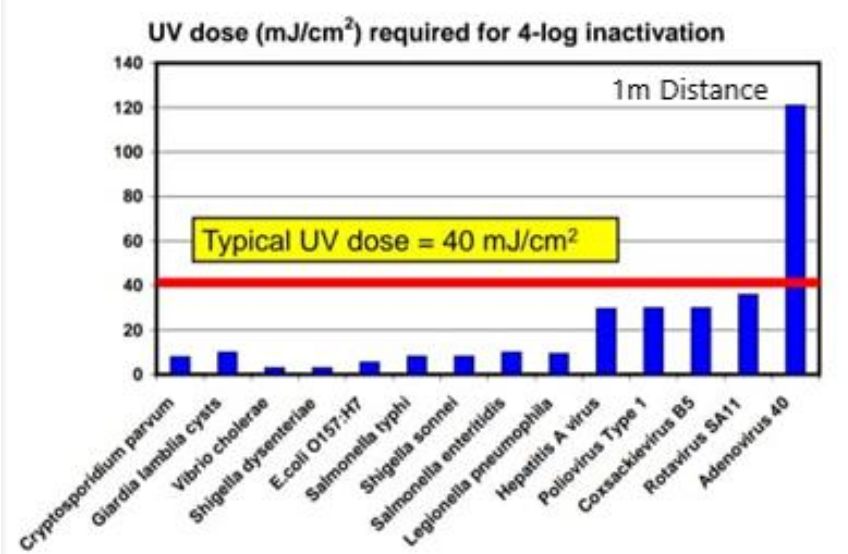

\section{Chart.1. UV Dosage}

From this the typical UV dosage must be $40 \mathrm{~mJ} / \mathrm{cm}^{2}$

$$
\begin{aligned}
1 \mathrm{~mJ} / \mathrm{cm}^{2} & =1 \mathrm{~mW} \cdot \mathrm{sec} / \mathrm{cm}^{2} \\
40 \mathrm{~mJ} / \mathrm{cm}^{2} & =40 \mathrm{~mW} \cdot \mathrm{sec} / \mathrm{cm}^{2} \\
& =40,000 \mu \mathrm{W} \cdot \mathrm{sec} / \mathrm{cm}^{2}
\end{aligned}
$$

For $99.99 \%$ of inactivation, dosage should be 4 $\log$ inactivation when the UVC is at a distance of 1 meter.

Here for our selected product the dosage is

$$
\begin{aligned}
\text { Intensity } & =51 \mu \mathrm{W} / \mathrm{cm}^{2} \\
\text { Dosage } & =40,000 \mu \mathrm{W} . \mathrm{sec} / \mathrm{cm}^{2} \\
\text { Time } & =40,000 / 51 \\
& =14 \text { min approx. }
\end{aligned}
$$

Hence the above equations states that it takes around $14 \mathrm{~min}$ time to destroy $99.99 \%$ with the dosage of $40 \mathrm{~mJ} / \mathrm{cm}^{2}$ when the distance between the source and target is 1 meter. And also, by the use of a blower the particles are disposed of and these microbes do not become a threat to the next person who uses it. By this method, it is safe and secure to use the regular biometric device.

Using inverse square law,

$$
I \propto 1 / d^{2}
$$

Where ' $I$ ' is the intensity of UVC light and ' $d$ ' is the distance between the light and the surface from which UVC light is emitted.

From this it is obvious that, intensity increases with the decrease in distance. Hence smaller the 
distance it doesn't take much time to destroy the microbes.

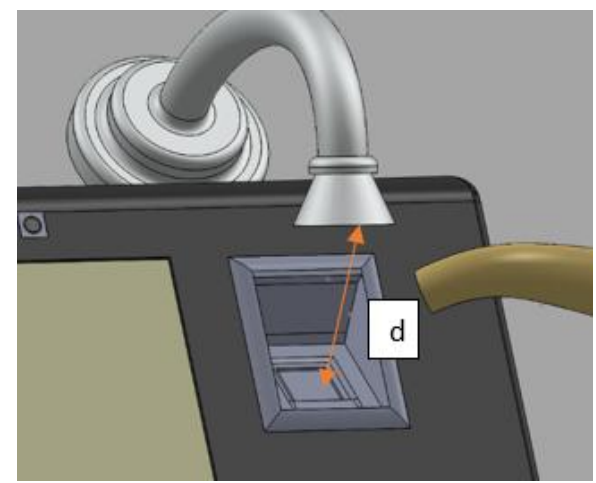

Fig.3. Distance 'd'

The distance between the fingerprint sensor and the light is 8 to $10 \mathrm{~cm}$ approx.

Time to subdue virus at $1 \mathrm{~m}$ distance $=14 \mathrm{~min}$ Time to subdue virus at $10 \mathrm{~cm}$ distance $=1.4 \mathrm{~min}$

$$
=84 \mathrm{sec}
$$

Increasing the power of the UVC lamp increases the intensity respectively. Using a UVC lamp of $18 \mathrm{~W}$ at a distance of $1 \mathrm{~m}$ is 14 minutes. Using $18 \mathrm{~W}$ lamp at a distance of $10 \mathrm{~cm}$ takes 84 sec to disintegrate the virus. Hence $100 \mathrm{~W}$ lamp at a distance of $10 \mathrm{~cm}$ decrease the overall time to disintegrate the virus.

Power of UVC light $=100 \mathrm{~W}$

Therefore, the ratio increase is by 6

Total time taken to disintegrate

$$
\begin{aligned}
& =84 / 6 \\
& =14 \mathrm{sec} \text { (approx.) }
\end{aligned}
$$

Hence $100 \mathrm{~W}$ lamp at a distance of $10 \mathrm{~cm}$ consumes $14 \mathrm{sec}$ to subdue virus present on the surface.

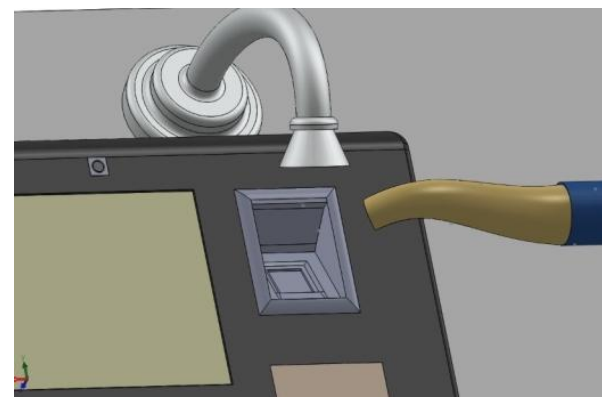

Fig.4. Detailed view showing the projections focussing the fingerprint sensor region

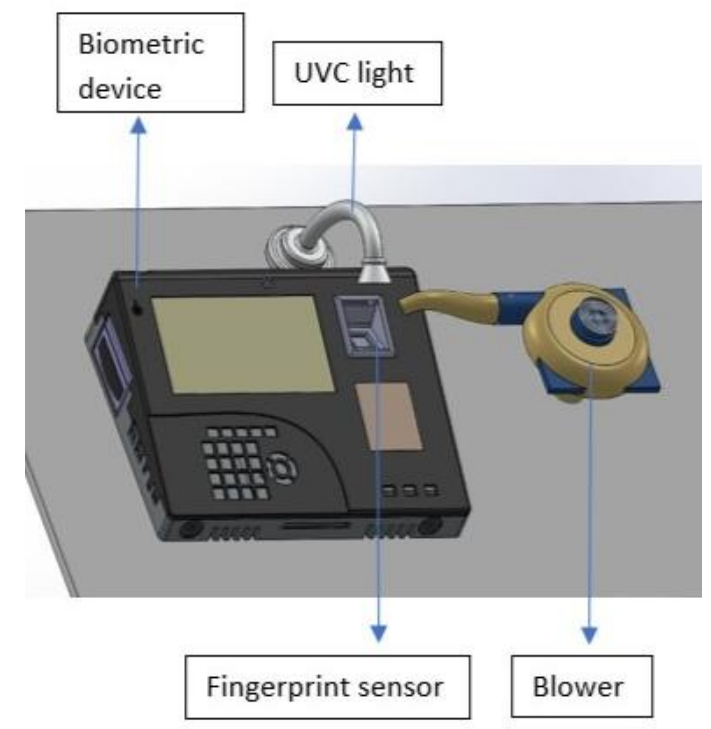

Fig.5. A Prototype of the devised model

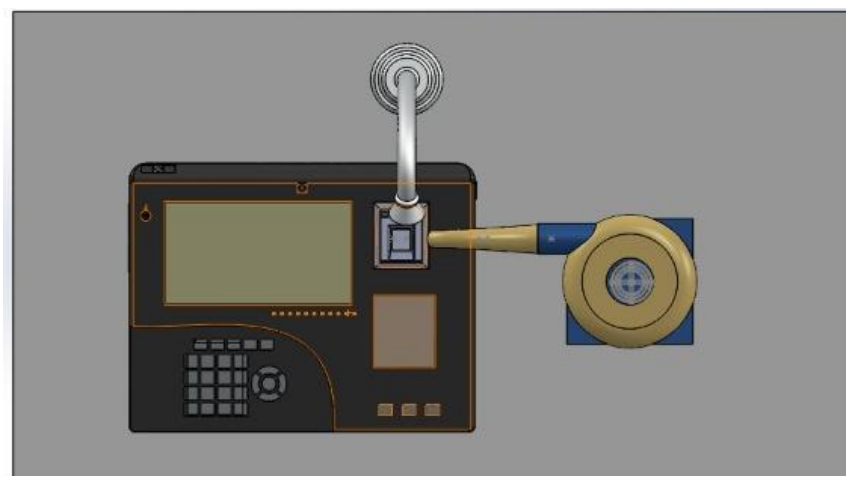

Fig.6. UVC Disinfectant over a Biometric Device

\section{Materials used}

\subsection{UVC LAMP}

UVC lights are readily available in stores. UVC lights are nontoxic, chemical free, rapid disinfection and safe to use. UVC lights when used destroy the molecular structure of DNA/RNA. Other specifications also include,

1. Wavelength: $207 \mathrm{~nm}-222 \mathrm{~nm}$

2. Power: $100 \mathrm{~W}$

3. Lifetime: 8000 - 10000 hours

(1-yearApprox.)

\subsection{Blower or Fan}

Using, Blower or a fan wipes away or dispose the dead virus present on the surface of the biometric sensor. This blower may also act as a means to cool down the surface due to the frequent 
www.rspsciencehub.com

exposure of UVC light. Other specifications also include,
1. Power: 12 V DC supply
2. Speed: 4500RPM
3. Current: 10amps
4. Airflow: $9.17 \mathrm{CFM}$

\section{Conclusion}

This UVC light in an automated way attached with a biometric device prevents the spread of any communicable virus. At this time, this method will prove efficient for the biometric device with safety measures too. Security plays a major role in our society to protect our information. Attendance serves as an important factor in many organizations. Due to a fear between employees, this Biometric system has been shut down and old traditional method have been employed in practice. Many organizations use pen and paper for attendance. But this method will ensure a comeback for attendance and security systems using regular biometric devices. Major hospitals use UV sanitisation for safety purposes too. Following the same way, this can be used for sanitizing the biometric touch thus stopping Community Spread.

\section{Acknowledgement}

We, authors of this manuscript thank our institution, for providing such a problem statement also encouraging students to research and explore a lot. We also thank each and every co-author for their continuous cooperation. We also extend our sincere thanks to Dr. Balasubramanian, for his patient approach and for his assistance throughout the way. This work is ostensibly supported by $\mathrm{M} / \mathrm{s}$.NavlesTechnologies, Coimbatore. We also extend our sincere thanks to $\mathrm{M} / \mathrm{s}$. Navles Technologies, Coimbatore.

\section{References}

\section{Websites}

[1.] Press Release: https://www.medicinenet.com/can_uv_ligh t_kill_or_prevent_coronavirus-news.htm
Volume 02 Issue 07 July 2020

[2.] https://www.britannica.com/science/corona virus-virus-group

\section{Article:}

[3.] Ebert, L. B. (1997). Science of fullerenes and carbon nanotubes. Carbon.35(3),437438

[4.] Is UVC safe?

https://www.klaran.com/is-uvc-safe

[5.] Buonanno, M.,Welch,D., Shuryak,1. Et al. Article number: 10285(2020) https://doi.org/10.1038/s42598-020-67211$\underline{2}$

\section{Patent:}

[6.] Kreiner et al (2018)

Patent No.: US9907871B2

Method and Apparatus for Sterilizing a Surface.

[7.] Garcia et al. (2010)

Patent No.: US7721383B2

Disinfecting Device using Ultraviolet Radiations.

[8.] Harmon et al.(2010)

Patent No.: US8105532B2

Mobile Disinfectant methods and device.

[9.] Ervin Keith (2018)

Patent No.:US 20180343847A1

Device and Method for disinfection and extermination using UVC lights.

[10.] Rosenthal et al. (2001)

Patent No.: US6254625B1

Hand Sanitizer.

\section{Websites}

[11.]https://www.webmd.com/lung/how-longcovid-19-lives-on-surfaces 